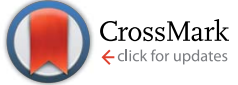

Cite this: RSC Adv., 2017, 7, 897

\title{
Design and synthesis of a castor oil based plasticizer containing THEIC and diethyl phosphate groups for the preparation of flame-retardant PVC materials
}

\author{
Puyou Jia, ${ }^{a}$ Lihong Hu, ${ }^{\text {ab }}$ Guodong Feng, ${ }^{a}$ Caiying Bo, ${ }^{a}$ Jing Zhou, ${ }^{a}$ Meng Zhang ${ }^{\star a b}$ \\ and Yonghong Zhou*a
}

\begin{abstract}
A fine chemical product based on a castor oil containing THEIC and diethyl phosphate groups (THEIC-MRphosphate) was designed and synthesized, and it was used as a substitute flame retardant plasticizer to prepare PVC materials instead of the commercial plasticizer dioctyl phthalate (DOP). The performance of the PVC materials plasticized with THEIC-MR-phosphate was investigated with TGA, DSC, cone calorimeter analysis, and tensile tests. The results indicated that the addition of THEIC-MR-phosphate improved the flame retardant properties of the PVC materials. The time to ignition ( $\mathrm{TI}$ ) increased from $10 \mathrm{~s}$ to $25 \mathrm{~s}$, the pHRR value decreased from $167.5 \mathrm{~kW} \mathrm{~m}^{-2}$ to $52.1 \mathrm{~kW} \mathrm{~m}^{-2}$, the av-HRR value decreased from $44.7 \mathrm{~kW} \mathrm{~m}^{-2}$ to $21.1 \mathrm{~kW} \mathrm{~m}^{-2}$, and the t-pHRR value increased from $45.0 \mathrm{~s}(\mathrm{D}-1)$ to $73.0 \mathrm{~s}(\mathrm{~N}-3)$. These data indicated that the THEIC-MR-phosphate was effective in increasing the PVC material resistance to fire, and it not only decreased the HRR, but also delayed the fire process.
\end{abstract}

Received 10th October 2016 Accepted 15th November 2016

DOI: $10.1039 / c 6 r a 25014 a$

www.rsc.org/advances alternate material sources for industrial uses. Nowadays, renewable resources have attracted increasing attention as non-petroleum raw materials to prepare chemical products. Hundreds of plasticizers derived from renewable resources have been commercially prepared or used, such as a cardanol-based plasticizer, ${ }^{3}$ epoxidized cardanol glycidyl ether, ${ }^{4}$ palm oil polyester, ${ }^{5}$ epoxidized cardanol diethyl phosphate, ${ }^{6}$ oleic acid polyester, ${ }^{7}$ isosorbide dicaprylate ester plasticizer ${ }^{8}$ and epoxidized soybean oil. ${ }^{9}$ The main chemical structure of the vegetable oil is triacylglycerol, and the main components of triglycerides are saturated and unsaturated fatty acids, which can be used as platform chemicals for many polymer and monomer synthesis. ${ }^{\mathbf{1 0}-13}$ However, these plasticizers cannot improve the flame retardant performance of PVC materials, which restricts their applications in harsh condition with high flame retardant requirements.

An effect way to improve the flame retardancy of PVC materials is to add flame retardants such as antimony trioxide $\left(\mathrm{Sb}_{2} \mathrm{O}_{3}\right),{ }^{14}$ alumina trihydrate, $\mathrm{Al}(\mathrm{OH})_{3},{ }^{15}$ or tripentyl phosphate, trimethyl phosphate, tris(chloropropyl) phosphate, and di- $n$ octylphenyl phosphate, ${ }^{\mathbf{1 6}}$ but the addition of flame retardants usually decreases the mechanical properties of PVC blends. It is necessary to prepare PVC materials using flame retardant plasticizers that can effectively improve both the mechanical and flame retardant properties of the PVC blends.

Our research group prepared a series of flame retardant plasticizers derived from vegetable oil and explored the retardant mechanism of PVC plasticized with the flame retardant
${ }^{a}$ Institute of Chemical Industry of Forest Products, Chinese Academy of Forestry (CAF), National Engineering Lab for Biomass Chemical Utilization, Key Lab on Forest Chemical Engineering, State Forestry Administration, Key Lab of Biomass Energy and Materials, 16 Suojin North Road, Nanjing 210042, Jiangsu Province, P. R. China.E-mail:yhzhou777@sina.com

${ }^{b}$ Institute of New Technology of Forestry, Chinese Academy of Forest (CAF), Beijing 100091, P. R. China 
plasticizers. The flame retardant plasticizer based on castor oil (PPC) was synthesized from castor oil, formic acid, phosphate, hydrogen peroxide $\left(\mathrm{H}_{2} \mathrm{O}_{2}\right)$ and diethyl phosphate. ${ }^{17}$ The diethyl phosphate connected to the chemical structure of glycerin trilaurate played the flame retardant role in the fire process. The flame-retardant performance of COPE was carried out by promoting PVC blend carbonization and forming a consolidated coating covered on the PVC matrix, which prevented the materials from firing. In order to improve the flame retardant performance of the plasticizer, the phosphorus content of the plasticizer was enhanced, and the new flame retardant plasticizer based on castor oil (FRC) was prepared and achieved the expected results. ${ }^{18}$ In addition, a soybean oil based phosphate ester (SOPE) was prepared using the same flame retardant group. ${ }^{19}$ All three kinds of vegetable oil based flame retardant plasticizers improved the thermal stability and flame retardancy of the PVC materials. However, the mechanical properties of the PVC materials gradually weakened with the addition of these plasticizers because many of the hydroxyl groups connected to the chemical structure of the plasticizers and reduced the plasticizing effect on the PVC. They are only used as a secondary plasticizer mixed with DOP to plastify the PVC resin. To enhance the plasticizing effect of the plasticizer, a new flame retardant chlorinated phosphate ester based on castor oil (CPECO) was prepared and applied in the PVC materials. ${ }^{20}$ Hydroxyl groups were not found in the chemical structure. The results illustrated that the thermal stability and flame retardancy of the PVC materials improved drastically, and the migration stability was better than that of DOP. However, the mechanical properties of the PVC materials were not obviously enhanced. The reason is that the macromolecular and branching structure of the plasticizer reduced the mobility of the PVC chain. Based on these reasons, it is necessary to prepare novel flame retardant plasticizers derived from vegetable oils as the main plasticizer for PVC resin.

In this work, we designed and synthesized a fine chemical product using castor oil containing THEIC and diethyl phosphate groups (THEIC-MR phosphate), and the product was used as a flame retardant plasticizer for PVC materials. Its chemical structure was characterized with FT-IR and ${ }^{1} \mathrm{H}$ NMR. The performance of the PVC materials plasticized with the THEIC-MR phosphate was investigated using TGA, DSC, cone tests and tensile tests. To the best of our knowledge, the synthesis and application of a castor oil based flame retardant plasticizer containing THEIC and diethyl phosphate groups for PVC has never been reported. We believe that a novel flame retardant plasticizer can be obtained from castor oil. Furthermore, flame retardant PVC materials can be prepared and used in harsh conditions. This study will provide a new route for the efficient use of castor oil.

\section{Experimental}

\subsection{Materials}

Castor oil, caustic potash $(\mathrm{KOH})$, anhydrous methanol, tetrabutyl titanate, tetrahydrofuran, 1,3,5-tris(2-hydroxyethyl) cyanuric acid (THEIC), diethyl chlorophosphate, concentrated sulfuric acid, chloroform, and dioctyl phthalate (DOP) were kindly provided by the Nanjing Chemical Reagent Co., Ltd. Polyvinyl chloride (PVC) was supplied by Hanwha (KM-31, South Korea).

\subsection{Synthesis}

2.2.1 Synthesis of methyl ricinoleate (MR). Castor oil ( $50 \mathrm{~g})$, anhydrous methanol $(10 \mathrm{~g})$ and $\mathrm{KOH}(0.45 \mathrm{~g})$ were mixed in a $250 \mathrm{~mL}$ flask with a mechanical agitator, thermometer and condenser tube with stirring at $45^{\circ} \mathrm{C}$ for $6 \mathrm{~h}$. Then, the mixture was neutralized with a sulfuric acid solution and allowed to settle in a liquid separating funnel. The upper oil liquid was washed with an acid solution and distilled water until the $\mathrm{pH}=$ 7. Methyl ricinoleate was obtained after removing the water with a rotary evaporator at $60{ }^{\circ} \mathrm{C}$.

2.2.2 Alcoholysis of castor oil methyl with THEIC (THEICMR). Methyl ricinoleate and THEIC in a $1: 1$ molar ratio were placed in a $250 \mathrm{~mL}$ flask. Tetrabutyl titanate ( $1 \mathrm{wt} \%$ of methyl ricinoleate) was added to the solution as a catalyst. The mixture was stirred at $230{ }^{\circ} \mathrm{C}$ for $3 \mathrm{~h}$ in a $\mathrm{N}_{2}$ environment. The THEICMR was obtained after washing with distilled water and removing the water with a rotary evaporator.

2.2.3 Synthesis of castor oil based flame retardant plasticizer containing THEIC and diethyl phosphate groups (THEICMR phosphate). THEIC-MR and diethyl chlorophosphate in a molar ratio of $1: 3$ were dissolved in $100 \mathrm{~mL}$ of chloroform. The mixture was placed in a $250 \mathrm{~mL}$ flask and stirred at $60{ }^{\circ} \mathrm{C}$ for $3 \mathrm{~h}$ to finish the reaction. The THEIC-MR phosphate was obtained after removing the chloroform with a rotary evaporator. The synthetic route for the THEIC-MR phosphate is presented in Fig. 1.

\subsection{Preparation of PVC materials}

The PVC resin and plasticizer (DOP and THEIC-MR phosphate) were dissolved in $100 \mathrm{~mL}$ of THF in accordance with the formulation shown in Table 1 . The mixture was thoroughly agitated using a mechanical agitator at $160 \mathrm{rpm}$ for $1 \mathrm{~h}$ at $60{ }^{\circ} \mathrm{C}$

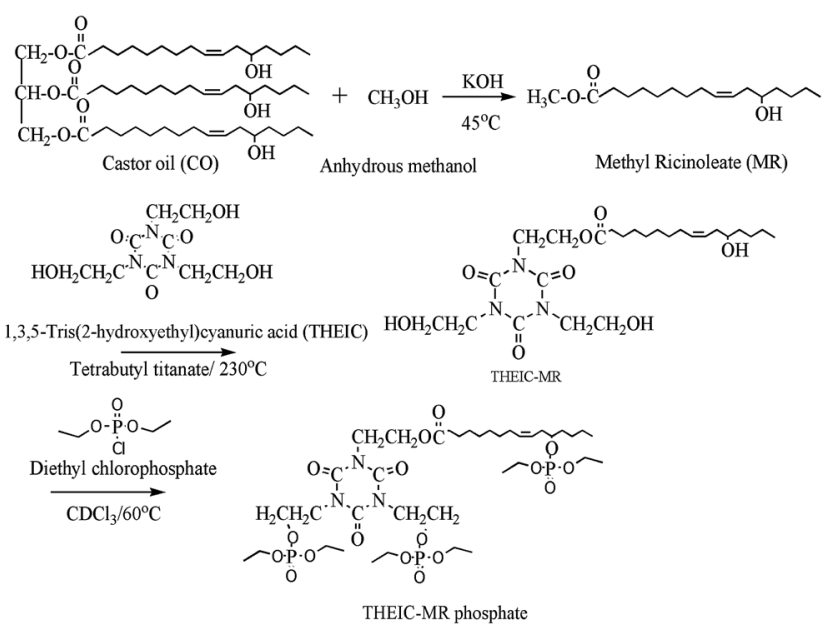

Fig. 1 Synthetic route of THEIC-MR phosphate. 
Table 1 Formulation of PVC materials

\begin{tabular}{llllll}
\hline PVC materials & PVC & D-1 & N-1 & N-2 & N-3 \\
\hline PVC $(\mathrm{g})$ & 20 & 20 & 20 & 20 & 20 \\
DOP $(\mathrm{g})$ & 0 & 12 & 9 & 6 & 0 \\
THEIC-MR phosphate $(\mathrm{g})$ & 0 & 0 & 3 & 6 & 12
\end{tabular}

until the mixture was clear and transparent. The samples were then placed in Petri dishes (diameter $12 \mathrm{~cm}$ ) and dried at ambient temperature for a week to remove traces of the residual solvent and to obtain thin films.

\subsection{Characterizations}

The Fourier transform infrared (FT-IR) spectra of the products were obtained on a Nicolet iS10 FTIR (Nicolet Instrument Crop., USA) Fourier transform infrared spectrophotometer. The spectra were acquired in the range of $4000 \mathrm{~cm}^{-1}$ to $500 \mathrm{~cm}^{-1}$ at a resolution of $4 \mathrm{~cm}^{-1}$.

${ }^{1} \mathrm{H}$ NMR measurements were conducted on an AV-300 NMR spectrometer (Bruker Instrument Crop., Germany) at a frequency of $400 \mathrm{MHz}$ with $\mathrm{CDCl}_{3}$ as the solvent and tetramethylsilane (TMS) as an internal standard.

Thermogravimetric analysis (TGA) was carried out using a TG209F1 TGA thermal analysis instrument (Netzsch Instrument Crop., Germany) in a $\mathrm{N}_{2}$ atmosphere $\left(50 \mathrm{~mL} \mathrm{~min}^{-1}\right)$ at a heating rate of $10^{\circ} \mathrm{C} \mathrm{min}^{-1}$. The samples $(5 \mathrm{mg})$ were placed into platinum pans and scanned from $40{ }^{\circ} \mathrm{C}$ to $600{ }^{\circ} \mathrm{C}$.

The glass transition temperature $\left(T_{\mathrm{g}}\right)$ was characterized using a NETZSCH DSC $200 \mathrm{PC}$ analyzer at a heating rate of $20^{\circ} \mathrm{C}$ $\min ^{-1}$ and scanning from $40{ }^{\circ} \mathrm{C}$ to $600{ }^{\circ} \mathrm{C}$.

The combustion properties were evaluated using a cone calorimeter. All samples $\left(100 \times 100 \times 2 \mathrm{~mm}^{3}\right)$ were exposed to a FTT200 cone calorimeter (FTT Instrument Crop., UK) under a heat flux of $35 \mathrm{~kW} \mathrm{~m}{ }^{-2}$ according to ISO-5660 standard procedures.

Tensile modulus, tensile strength, and elongation at break for all the PVC blends were determined according to GB/T 1040.1-2006 (China) under ambient conditions using an E43.104 Universal Testing Machine (MTS Instrument Crop., China).

The migration degree of the plasticizer was tested according to ASTMD1239-98 and our previous work. ${ }^{20}$

Anti-aging tests were carried out with a thermal aging oven at $185{ }^{\circ} \mathrm{C}$. Anti-aging properties were evaluated by observing the change in color with increasing time.

\section{Results and discussion}

\subsection{Synthesis and characterization of the plasticizer}

The successful preparation of THEIC-MR phosphate was confirmed by FT-IR. Fig. 2 shows the FT-IR spectra of castor oil, MR, THEIC-MR and THEIC-MR phosphate. The FT-IR spectrum of castor oil was detected in our previous study. ${ }^{17}$ After alcoholysis with anhydrous methanol, a stronger absorption peak appeared at around $3410 \mathrm{~cm}^{-1}$ in the FT-IR spectrum of

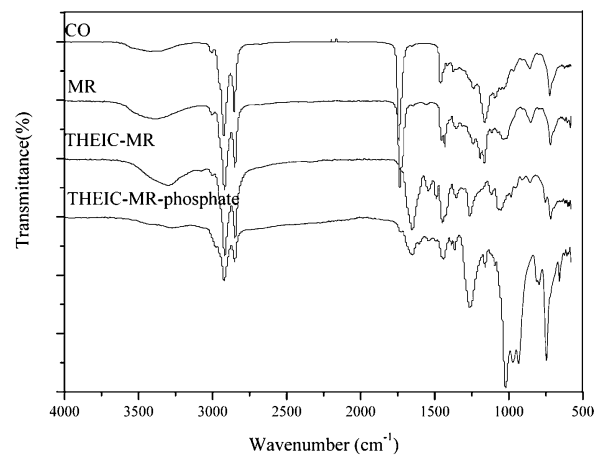

Fig. 2 FT-IR spectra of products.

MR compared to that of castor oil, which was attributed to the hydroxyl absorption peak of MR. ${ }^{17,18}$ In the THEIC-MR spectrum, a stronger absorption peak appeared at around 3297 $\mathrm{cm}^{-1}$, corresponding to the hydroxyl absorption peak of the THEIC groups. The carbonyl groups $(\mathrm{C}=\mathrm{O})$ of THEIC-MR appeared at $1659 \mathrm{~cm}^{-1}$, and the tertiary amine of THEIC-MR appeared at $1124 \mathrm{~cm}^{-1}$, indicating MR alcoholysis with THEIC. Comparing the spectrum to that of THEIC-MR showed that the hydroxyl absorption peak disappeared at around $3297 \mathrm{~cm}^{-1}$ in the THEIC-MR phosphate spectrum and a new absorption peak appeared at $1027 \mathrm{~cm}^{-1}$, which was attributed to the vibration absorption peak of $\mathrm{P}-\mathrm{O}-\mathrm{C}$. The vibration absorption peak of $\mathrm{P}-\mathrm{C}$ appeared at $977 \mathrm{~cm}^{-1}$, and another new absorption peak appeared at $800 \mathrm{~cm}^{-1}$, which corresponded to the vibration absorption peak of $\mathrm{P}-\mathrm{O}-\mathrm{CH}_{2} \mathrm{CH}_{3} \cdot{ }^{17,18}$

The successful preparation of the THEIC-MR phosphate was also detected with ${ }^{1} \mathrm{H}$ NMR. The ${ }^{1} \mathrm{H}$ NMR spectrum of castor oil was detected in our previous study. Fig. 3 presents the ${ }^{1} \mathrm{H}$ NMR spectrum of MR, and as seen in Fig. 3, the peak for the protons of the $-\mathrm{OH}$ at $\delta=1.3$ were weaker than that seen in castor oil. The peaks for the protons of - $\left(\mathrm{CH}_{2}\right)$ - connected to the glycerol ester could not be observed at 4.1-4.3 ppm, which indicated that the alcoholysis reaction occurred between the castor oil and anhydrous methanol. ${ }^{17,18}$ Fig. 4 presents the ${ }^{1} \mathrm{H}$ NMR spectrum of THEIC-MR. New peaks appeared at $4.0 \mathrm{ppm}$ and $4.2 \mathrm{ppm}$ compared to the ${ }^{1} \mathrm{H}$ NMR spectrum of MR, and these peaks were attributed to the protons of the $-\left(\mathrm{CH}_{2}\right)-$ of the THEIC groups in THEIC-MR. Multiple absorption peaks appeared at $3.5 \mathrm{ppm}$ and $3.6 \mathrm{ppm}$ and corresponded to the protons of the different $-\mathrm{OH}$ groups in THEIC-MR. These data illustrated that THEIC-MR was obtained. The ${ }^{1} \mathrm{H}$ NMR

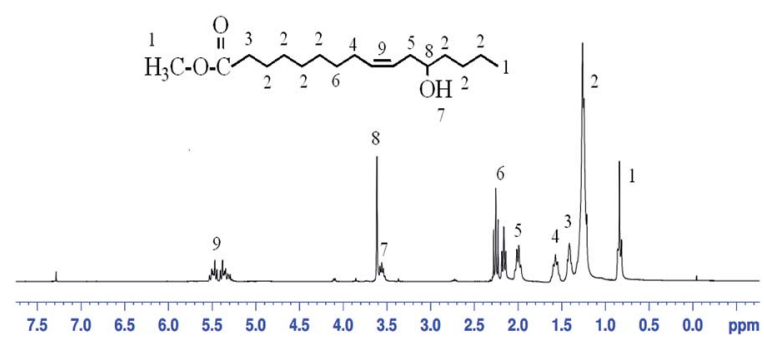

Fig. $3{ }^{1} \mathrm{H}$ NMR spectrum of MR. 


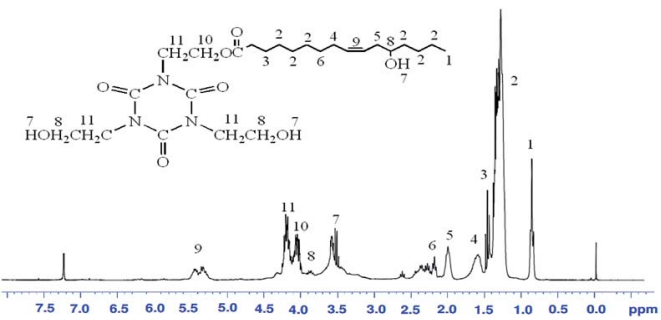

Fig. $4{ }^{1} \mathrm{H}$ NMR spectrum of THEIC $-M R$.

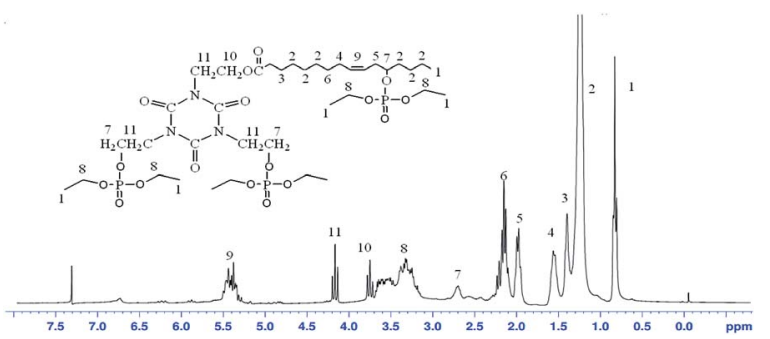

Fig. $5{ }^{1} \mathrm{H}$ NMR spectrum of THEIC-MR-phosphate.

spectrum of the THEIC-MR phosphate is shown in Fig. 5, and the absorption peak at $0.7 \mathrm{ppm}$ is attributed to the protons of $-\mathrm{CH}_{3}$ in THEIC-MR phosphate. These protons appeared to be stronger than that seen in THEIC-MR, and the absorption peak at $2.6 \mathrm{ppm}$ corresponded to the protons of $-\left(\mathrm{CH}_{2}\right)_{n}-$ in the THEIC-MR phosphate. ${ }^{19,20}$ In addition, the absorption peak at $3.6 \mathrm{ppm}$ was weaker than that of THEIC-MR, and all of the results indicated that THEIC-MR-phosphate was obtained.

\subsection{Performance of the plasticizer and property of the PVC materials}

3.2.1 TGA of PVC materials. TGA was used to investigate the thermal degradation behaviors of the PVC materials. Fig. 6 presents the TGA curves of the PVC materials. As seen from Fig. 6, all of the TGA curves exhibited two steps in the thermal degradation. The first step in the temperature range $200-350{ }^{\circ} \mathrm{C}$ corresponded to dehydrochlorination ${ }^{\mathbf{2 1 , 2 2}}$ and thermal decomposition of the plasticizer (DOP and THEIC-MR-phosphate). The second step occurred between 350 and $500{ }^{\circ} \mathrm{C}$ and was attributed to the cyclization of the conjugated polyene sequences to form aromatic compounds. ${ }^{23-25}$ The thermal degradation rate increased gradually with the replacement of

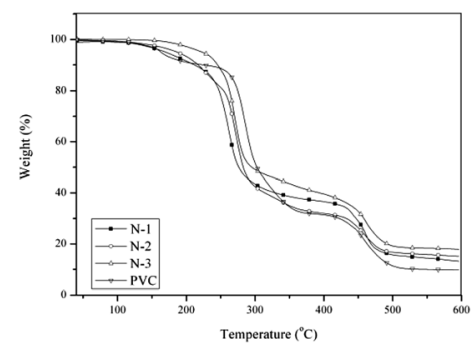

Fig. 6 TGA curves of PVC materials.
DOP and THEIC-MR-phosphate in the temperature range of 300-500 ${ }^{\circ} \mathrm{C}$. This illustrated that the THEIC-MR-phosphate enhanced the thermal stability of the PVC materials in the temperature range $300-500{ }^{\circ} \mathrm{C}$. The carbon residue rate of $\mathrm{D}-1$, $\mathrm{N}-1, \mathrm{~N}-2$ and $\mathrm{N}-3$ was $8.60,13.11,15.08$ and $17.78 \%$, respectively, at $600{ }^{\circ} \mathrm{C}$. The char residue of the PVC materials increased gradually with the addition of the THEIC-MRphosphate, which proved that the THEIC-MR-phosphate enhanced the char yield.

3.2.2 DSC of PVC materials. DSC was used to probe the glass transition temperature $\left(T_{\mathrm{g}}\right)$ of the PVC materials. $T_{\mathrm{g}}$ is a good criterion for determining the chain mobility of the polymers and compatibility of the PVC and plasticizer. ${ }^{26-29}$ It is essential to study the $T_{\mathrm{g}}$ of plasticizers for practical application as a plasticizer, which leads to a softening or plasticization of the polymeric materials. Fig. 7 shows the DSC curves of the PVC materials. PVC exhibited an exothermic peak at approximately $87.6{ }^{\circ} \mathrm{C}$. The $T_{\mathrm{g}}$ of N-1, N-2 and N-3 increased gradually as DOP was replaced with THEIC-MR-phosphate in the PVC materials. The $T_{\mathrm{g}}$ of $\mathrm{N}-1, \mathrm{~N}-2$ and $\mathrm{N}-3$ were $34.9{ }^{\circ} \mathrm{C}, 46.4{ }^{\circ} \mathrm{C}$ and $67.4{ }^{\circ} \mathrm{C}$, respectively. The drop in $T_{\mathrm{g}}$ for the PVC materials corresponds to a general increase in disorder, free volume, and mobility of the macromolecules. The results indicated that the compound plasticizer (DOP and THEIC-MR-phosphate) reduced the $T_{\mathrm{g}}$ of the PVC materials; the plasticizing effect of DOP was lower than that of the THEIC-MR-phosphate.

3.2.3 Cone calorimetric tests. There are many chlorine groups connected to the chemical structure of PVC, and they make PVC hard to burn. The addition of flammable DOP makes PVC materials easy to burn. Cone tests were used to investigate the combustibility of PVC materials when DOP was replaced with THEIC-MR-phosphate. These tests can provide data to study the thermal degradation, smoking emission and heat release in detail. ${ }^{\mathbf{3 0 , 3 1}}$ The detail cone calorimeter data were collected from cone tests and are shown in Table 2. The peak HRR (pHRR) value, average HRR (av-HRR), time to ignition, total smoke release, time to peak of HRR (t-pHRR), peak MLR (pMLR), THR and average MLR (av-MLR) of the PVC materials were compared. As can be seen in Table 2, the time to ignition (TI) increased from $10 \mathrm{~s}(\mathrm{D}-1)$ to $25 \mathrm{~s}(\mathrm{~N}-3)$, indicating that the THEIC-MR-phosphate made PVC materials more difficult to burn than the DOP. In the meantime, the pHRR value decreased from $167.5 \mathrm{~kW} \mathrm{~m}^{-2}$ (D-1) to $52.1 \mathrm{~kW} \mathrm{~m}^{-2}$ (N-3). The av-HRR

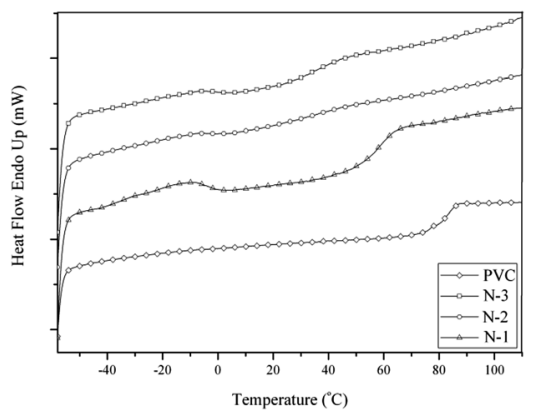

Fig. 7 DSC curves of PVC blends. 
Table 2 The detailed cone calorimeter data

\begin{tabular}{lllllllll}
\hline Sample & $\begin{array}{l}\text { pHRR } \\
\left(\mathrm{kW} \mathrm{m}^{-2}\right)\end{array}$ & $\begin{array}{l}\text { av-HRR } \\
\left(\mathrm{kW} \mathrm{m}^{-2}\right)\end{array}$ & $\begin{array}{l}\mathrm{t} \text {-pHRR } \\
(\mathrm{s})\end{array}$ & $\begin{array}{l}\text { pMLR } \\
\left(\mathrm{g} \mathrm{s}^{-1}\right)\end{array}$ & $\begin{array}{l}\text { av-MLR } \\
\left(\mathrm{g} \mathrm{s}^{-1}\right)\end{array}$ & $\begin{array}{l}\text { THR } \\
\left(\mathrm{MJ} \mathrm{m}^{-2}\right)\end{array}$ & $\begin{array}{l}\text { Time to ignition } \\
(\mathrm{TI})(\mathrm{s})\end{array}$ & $\begin{array}{l}\text { Total smoke release } \\
\left(\mathrm{m}^{2} \mathrm{~m}^{-2}\right)\end{array}$ \\
\hline D-1 & 167.5 & 44.7 & 45.0 & 0.227 & 0.039 & 9.0 & 10 & 663.0 \\
N-1 & 144.8 & 43.4 & 60.0 & 0.224 & 0.025 & 8.5 & 17 & 540.0 \\
N-2 & 118.3 & 34.4 & 65.0 & 0.186 & 0.009 & 5.6 & 18 & 497.0 \\
N-3 & 52.1 & 21.1 & 73.0 & 0.172 & 0.001 & 4.6 & 25 & 246.0
\end{tabular}

value decreased from $44.7 \mathrm{~kW} \mathrm{~m}^{-2}$ (D-1) to $21.1 \mathrm{~kW} \mathrm{~m}^{-2}(\mathrm{~N}-3)$, and the t-pHRR value increased from $45.0 \mathrm{~s}(\mathrm{D}-1)$ to $73.0 \mathrm{~s}(\mathrm{~N}-3)$. These data indicated that the THEIC-MR-phosphate was effective in suppressing the susceptibility of PVC materials to fire, as they not only decreased the HRR, but also delayed the fire process. The decrease of THR from $9.0 \mathrm{MJ} \mathrm{m}^{-2}$ (D-1) to 4.6 MJ $\mathrm{m}^{-2}(\mathrm{~N}-3)$ further showed that the THEIC-MR-phosphate acted as a flame retardant plasticizer for PVC.

The peak MLR (pMLR) and average MLR (av-MLR) for D-1 were $0.227 \mathrm{~g} \mathrm{~s}^{-1}$ and $0.039 \mathrm{~g} \mathrm{~s}^{-1}$, respectively. However, when DOP was replaced with THEIC-MR-phosphate, these parameters for N-3 were lower than that of D-1. The results indicated that the flame retardant effect of THEIC-MR-phosphate came from promoting the formation of the char residue, which could firmly protect the underlying PVC material from burning.

HRR is used to evaluate the combustion performance of PVC materials. The HRR curves of the PVC materials are presented in Fig. 8. A significant difference between the HRR curves of D-1 and the others was a sharp and high peak at around $41 \mathrm{~s}$ in the HRR curve of D-1. The peak of HRR gradually became flat and low as the DOP was replaced with THEIC-MR-phosphate, which can be observed in Fig. 8 (N-1, N-2 and N-3). The times of the HRR peak for N-1, N-2 and N-3 were $60 \mathrm{~s}, 65 \mathrm{~s}$ and $73 \mathrm{~s}$, respectively. These data illustrated that once the PVC materials were ignited, D-1 burnt and released heat quickly. However, $\mathrm{N}-1, \mathrm{~N}-2$ and $\mathrm{N}-3$ were hard to burn and released less heat than $\mathrm{D}-1$. The reason for this is that the THEIC-MR-phosphate promoted the formation of compact and expansive charred layers that covered the surface of the PVC matrix, and these layers acted as excellent barriers to mass transport and as heat insulation. The conclusion was consistent with the char residue after the cone tests.

To evaluate the smoke suppression performance of PVC materials, the smoke production rate (SPR) with time is shown in Fig. 9. The obvious difference between D-1 and the others
(N-1, N-2 and N-3) was that the SPR curves of D-1 were higher and sooner than the others. This indicated that D-1 released more smoke after the fire than the others. The smoke was mainly a compound of combustion. The other PVC materials plasticized with THEIC-MR-phosphate released less smoke because the thermal degradation of the THEIC-MR-phosphate promoted the formation of a char residue. The char residue acts as a smoke-suppressant in the combustion of PVC materials. The smoke-suppressant effect caused the lags in the SPR peaks of $\mathrm{N}-1, \mathrm{~N}-2$ and $\mathrm{N}-3$.

Fig. 10 shows the MLR curves of the PVC materials. Two mass loss stages could be observed, and these are attributed to the two mass loss stages of the PVC materials. This was similar to the TGA curves. The mass loss of the PVC materials occurred before $50 \mathrm{~s}$, which corresponded to the $\mathrm{HCl}$ elimination reaction. The cyclization of the conjugated polyene sequences to form aromatic compounds occurred after $50 \mathrm{~s}$. The mass loss was caused by the thermal degradation of PVC materials and mainly produced smoke. The MLR curves of D- 1 were higher than that of the other materials throughout the whole combustion process, which illustrated that the PVC materials plasticized with THEIC-MR-phosphate released less smoke than D-1, and THEIC-MR-phosphate provided a smoke suppression effect during the whole combustion process. Furthermore, more char residue was retained in the solid phase, and the formed char residue covered the surface of the PVC matrix. It made the PVC materials ( $-1, \mathrm{~N}-2$ and $\mathrm{N}-3)$ more thermally stable and flame retardant compared to D-1.

In addition, the THR curves of the PVC materials are shown in Fig. 11. The detailed THR data are summarized in Table 2. It can be found that the THR decreased from $9.0 \mathrm{MJ} \mathrm{m}^{-2}$ (D-1) to 4.6 $\mathrm{MJ} \mathrm{m} \mathrm{m}^{-2}$ with the addition of the THEIC-MR-phosphate. Fig. 10 shows that the THR value of D-1 was less than that of

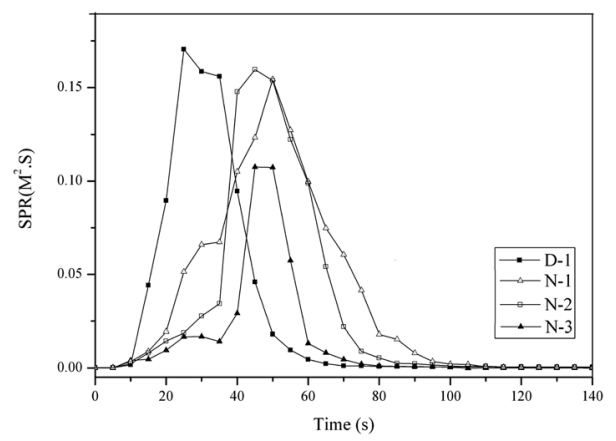

Fig. 9 SPR curves of PVC blends.

Fig. 8 HRR curves of PVC blends. 


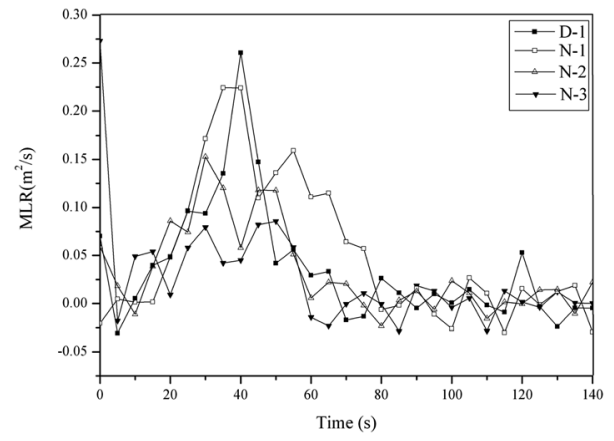

Fig. 10 MLR curves of PVC blends.

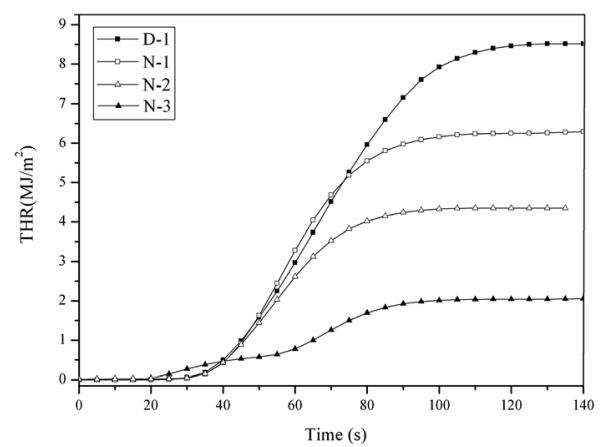

Fig. 11 THR curves of PVC blends.

the other PVC materials for the whole combustion process. The results indicated that the THEIC-MR-phosphate decreased the THR of the PVC materials.

Fig. 12 shows the TSR curves of the PVC materials. The MLR data illustrated that the THEIC-MR-phosphate had a smoke suppression effect during the whole combustion process. The TSR curves further proved that conclusion. As seen in Fig. 12, the TSR value was the highest after $60 \mathrm{~s}$. The time occurred just after cyclization of conjugated polyene sequences to form aromatic compounds. The results indicated that the smoke released after the cyclization process of the conjugated polyene sequences. An interesting phenomenon could be found by comparing the TSR curves and THR curves. The trend of the THR curves is similar to the TSR curves but always lagged behind the TSR curves. We can infer that the burning of the PVC materials was in fact the burning of the char residue.

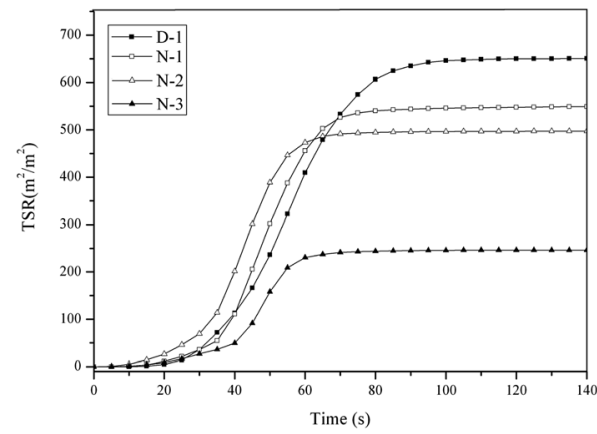

Fig. 12 TSR curves of PVC blends
3.2.4 Tensile tests. The tensile strength, elongation at break and modulus of elasticity were used to evaluate the plasticizing effect of the plasticizer. Table 3 shows the tensile strength, elongation at break and modulus of elasticity of all the PVC materials. Pure PVC showed a higher tensile strength of 26.60 MPa and lower elongation at break of $167.21 \%$ compared to the others. The addition of DOP into the PVC blends caused a significant decrease of $13.08 \mathrm{MPa}$ in the tensile strength and an increase in the elongation at break of 605.35. When DOP was gradually substituted with THEIC-MR-phosphate in the PVC materials, the tensile strength of the PVC blends increased from 13.08 MPa (D-1) to 15.20 MPa (N-3), and the elongation at break decreased from 605.35 (D-1) to $391.98 \%$ (N-3). These data indicated that the plasticizing effect of the THEIC-MR-phosphate was lower than that of DOP. The DSC data further illustrated that the plasticizing effect of the THEIC-MR-phosphate was lower than the DOP. We inferred that the compatibility of DOP with PVC was better than that of the THEIC-MR-phosphate. The smaller relative molecular mass and ortho phenyl ester structure make DOP easier to dissolve in the PVC matrix.

3.2.5 Migration stability. Fig. 13 presents the migration degree of all PVC materials. As seen from Fig. 13, the loss of the plasticizer in D-1 in four different solvents was more than the others. The resistance performance of migration for D-1 in distilled water, $30 \%(\mathrm{w} / \mathrm{v})$ acetic acid, $10 \%(\mathrm{v} / \mathrm{v})$ ethanol and petroleum ether was $1.40,1.54,1.55$ and $3.45 \%$, respectively. The degree of migration decreased obviously with the addition of THEIC-MR-phosphate. The resistance performance of migration for $\mathrm{N}-3$ in distilled water, $30 \%(\mathrm{w} / \mathrm{v})$ acetic acid, $10 \%(\mathrm{v} / \mathrm{v})$ ethanol and petroleum ether was $0.97,0.87,0.92$ and $1.91 \%$, respectively. This data illustrated that the resistance performance of migration for the THEIC-MR-phosphate was better than that of the DOP. The reason is that the large molecular weight and high degree of branching make THEIC-MR-phosphate harder to migrate in the PVC matrix. The better resistance performance of migration can help stabilize the properties of PVC materials.

3.2.6 Anti-aging tests. The plasticized PVC materials were put into a thermal aging oven. The temperature was kept at $185^{\circ} \mathrm{C}$. Anti-aging properties were evaluated by observing the change of color with time. The results showed that the time for the color change was prolonged from $8 \mathrm{~min}$ to $78 \mathrm{~min}$ with the addition of THEIC-MR-phosphate. The color change for D- $1, \mathrm{~N}$ $1, \mathrm{~N}-2$ and $\mathrm{N}-3$ was $8,26,57$ and $78 \mathrm{~min}$, respectively. The time was extended nearly four times. In addition, the TGA tests showed that the thermal stability of the PVC materials was enhanced with the addition of THEIC-MR-phosphate. These

Table 3 The mechanical properties of the PVC blends

\begin{tabular}{llll}
\hline Sample & $\begin{array}{l}\text { Tensile strength } \\
(\mathrm{MPa})\end{array}$ & $\begin{array}{l}\text { Elongation at } \\
\text { break (\%) }\end{array}$ & $\begin{array}{l}\text { Modulus of } \\
\text { elasticity (MPa) }\end{array}$ \\
\hline PVC & 26.60 & 167.21 & 197.11 \\
D-1 & 13.08 & 605.35 & 56.93 \\
N-1 & 14.12 & 527.10 & 76.23 \\
N-2 & 14.78 & 482.04 & 96.12 \\
N-3 & 15.20 & 391.98 & 115.81
\end{tabular}




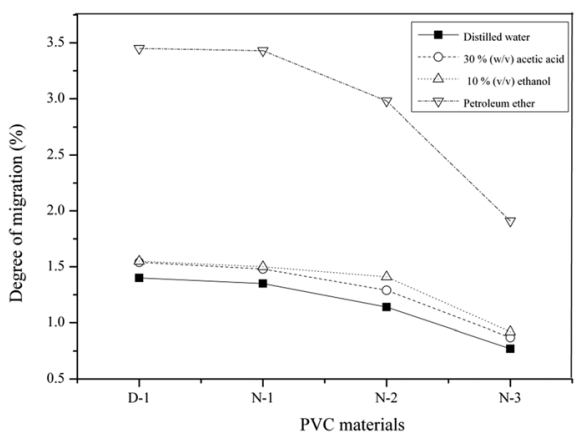

Fig. 13 Migration stability of PVC materials.

results showed that the THEIC-MR-phosphate improved the heat resistance of PVC materials.

\section{Conclusions}

In this study, we designed and synthesized a novel fine chemical product based on castor oil containing THEIC and diethyl phosphate groups. The product was used as a flame retardant plasticizer for preparing flame PVC materials. FT-IR spectra and ${ }^{1} \mathrm{H}$ NMR were used to characterize its chemical structure, and they indicated that the castor oil based flame retardant plasticizer was prepared successfully. The performances of the PVC materials plasticized with THEIC-MR-phosphate were investigated. The results illustrated that the THEIC-MR-phosphate enhanced the thermal stability of PVC materials in the temperature range of 300$500{ }^{\circ} \mathrm{C}$. DSC and tensile tests indicated that the compound plasticizer (DOP and THEIC-MR-phosphate) reduced the $T_{\mathrm{g}}$ of the PVC materials; the plasticizing effect of DOP was lower than that of the THEIC-MR-phosphate, but it can still be used as the main plasticizer in rigid PVC materials with high flame retardant requirements. The flame retardant effect of the THEIC-MR-phosphate was obtained by promoting the formation of a char residue that could protect the underlying PVC material from burning. The trends of the THR curves are similar to the TSR curves, but they always lagged behind the TSR curves. The burning of the PVC materials was in fact the burning of the char residue. This study will provide a new route for the efficient use of castor oil.

\section{Acknowledgements}

This work was supported by Jiangsu Key Lab of Biomass-based Green Fuels and Chemicals; the Fundamental Research Funds from Jiangsu Province Biomass and Materials Laboratory (JSBEM-S-2017010); National Natural Science Foundation of China (Grant No. 31670578); the President of the Chinese Academy of Forestry Foundation (Grant No. CAFYBB2014QB021).

\section{Notes and references}

1 P. Jia, M. Zhang, L. Hu and Y. Zhou, Korean J. Chem. Eng., 2016, 33, 1080-1087.

2 J. A. Tickner, T. Schettler, T. Guidotti, M. McCally and M. Rossi, Am. J. Ind. Med., 2001, 39, 100-111.
3 P. Yang, J. Yan, H. Sun, H. Fan, Y. Chen, F. Wang and B. Shi, RSC Adv., 2015, 5, 16980-16985.

4 J. Chen, Z. Liu, J. Jiang, X. Nie, Y. Zhou and R. E. Murray, RSC Adv., 2015, 5, 56171-56180.

5 P. Jia, M. Zhang, L. Hu and Y. Zhou, Pol. J. Chem. Technol., 2016, 18, 9-14.

6 J. Chen, Z. Liu, X. Li, P. Liu, J. Jiang and X. Nie, Polym. Degrad. Stab., 2016, 126, 58-64.

7 M. M. Sander, A. Nicolau, R. Guzatto and D. Samios, Polym. Test., 2012, 31, 1077-1082.

8 C. Cui, Y. Zhen, J. Qu, B. Chen and T. Tan, RSC Adv., 2016, 6, 11959-11966.

9 P. Karmalm, T. Hjertberg, A. Jansson and R. Dahl, Polym. Degrad. Stab., 2009, 94, 2275-2281.

10 S. B. Lee, J. D. Lee and I. K. Hong, J. Ind. Eng. Chem., 2011, 17, 138-143.

11 S. K. Olssona, H. Matsunagab, Y. Kataokab, M. Johanssonc, J. Matsumurad, M. Westine and E. Östmarka, Polym. Degrad. Stab., 2015, 13, 40-45.

12 M. Heinen, A. E. Gerbase and C. L. Petzhold, Polym. Degrad. Stab., 2014, 108, 76-86.

13 P. Jia, M. Zhang, L. Hu, G. Feng, C. Bo and Y. Zhou, ACS Sustainable Chem. Eng., 2015, 3, 2187-2193.

14 X. Yin and J. Zhang, RSC Adv., 2016, 6, 46060-46067.

15 S. V. Levchik and E. D. Weil, Polym. Adv. Technol., 2004, 15, 691-700.

16 A. Marklund, B. Andersson and P. Haglund, J. Environ. Monit., 2005, 7, 814-819.

17 P. Jia, C. Bo, L. Zhang, L. Hu, M. Zhang and Y. Zhou, J. Ind. Eng. Chem., 2015, 28, 217-224.

18 G. Feng, P. Jia, L. Zhang, L. Hu, M. Zhang and Y. Zhou, Korean J. Chem. Eng., 2015, 32, 1201-1206.

19 P. Jia, M. Zhang, C. Liu, L. Hu and Y. Zhou, J. Appl. Polym. Sci., 2015, DOI: 10.1002/app.42111.

20 P. Jia, M. Zhang, C. Liu, L. Hu, G. Feng, C. Bo and Y. Zhou, RSC Adv., 2015, 5, 41169-41178.

21 P. Jia, M. Zhang, L. Hu, J. Zhou, G. Feng and Y. Zhou, Polym. Degrad. Stab., 2015, 121, 292-302.

22 Y. Soudais, L. Moga, J. Blazek and F. Lemort, J. Anal. Appl. Pyrolysis, 2007, 78, 45-57.

23 Q. Yao and C. A. Wilkie, J. Vinyl Addit. Technol., 2001, 7, 26-36. 24 M. A. D. Silva, M. G. A. Vieira, A. C. G. Maçumoto and M. M. Beppu, Polym. Test., 2011, 30, 478-484.

25 Y. Pan and D. Wang, RSC Adv., 2015, 5, 27837-27843.

26 Y. Li, C. Wang and Z. Qu, J. Wuhan Univ. Technol., Mater. Sci. Ed., 2008, 2, 101-104.

27 T. B. Mohamed and M. Valérie, J. Appl. Polym. Sci., 2010, 118, 3499-3508.

28 J. W. Barlow and D. R. Paul, Annu. Rev. Mater. Res., 1981, 11, 299-319.

29 N. Gil, M. Saska and I. Negulescu, J. Appl. Polym. Sci., 2006, 102, 1366-1373.

30 Y. Fang, Q. Wang, C. Guo, Y. Song and P. A. Cooper, J. Anal. Appl. Pyrolysis, 2013, 100, 230-236.

31 M. Scudmore, P. Briggs and F. Prager, Fire Mater., 1991, 15, 65-84. 